\title{
O CIRCO CHEGOU À CIDADE! OPORTUNIDADES DE INOVAÇÃO SÓCIO-TERRITORIAL
}

\author{
ISABEL ANDRÉ ${ }^{1}$ \\ JOÃO REIS ${ }^{1}$
}

\begin{abstract}
Resumo - Este artigo discute o papel das artes, e do circo em particular, na construção de meios socialmente criativos que impulsionam, através da inovação social, o desenvolvimento dos lugares. Estes meios - bairros, cidades ou regiões - conjugam normalmente diversidade, tolerância, participação e memória colectiva e o circo, enquanto meio artístico, associa bem essas quatro características. Para compreender mais detalhadamente a relação do circo com a inovação social analisamos o caso específico do Chapitô, em Lisboa. A presença do Chapitô na cidade, através de múltiplas actividades que ligam as artes circenses à inclusão social, é um dado adquirido e amplamente reconhecido. Contudo, parece haver alguma dificuldade em protagonizar um "salto qualitativo" que permita, por um lado, alargar a escala de actuação desta instituição e, por outro, passar para um patamar de qualificação mais elevado. Numa leitura mais ampla, consideramos que as artes circenses denotam uma capacidade assinalável para impulsionarem a inovação sócio-territorial, tanto através da qualificação do espaço público urbano como por via da inclusão social de crianças e jovens em risco.
\end{abstract}

Palavras-chave: Inovação social, inovação sócio-territorial, meios socialmente criativos, cidade, circo.

\begin{abstract}
THE CIRCUS IS IN TOWN! OPPORTUNITIES FOR SOCIOTERRITORIAL INNOVATION. This article discusses the role of the arts, and the circus in particular, in engendering socially creative milieux that promote place development through social innovation. These milieux - neighbourhoods, cities or regions - typically combine diversity, tolerance, participation and collective memory - features that also characterise the circus as an artistic milieu. In order to gain a deeper understanding of the relationship between the circus and social innovation, we focus on the case of Chapitô, in Lisbon. Chapitô's presence in the city, through a variety of activities that bring together circus arts and social inclusion, is an acquired and widely acknowledged fact. However, something seems to be preventing the possibility of a "qualitative
\end{abstract}

Recebido: 18/12/2008. Revisto: 14/02/2009. Aceite: 20/02/2009.

1 Centro de Estudos Geográficos, Universidade de Lisboa.

Email: isabelandre@fl.ul.pt; reis97@gmail.com 
leap" that would allow this organisation to grow in terms of the scale of its activities, on the one hand, and for it to improve its own internal pool of skills and qualifications, on the other. Some broader conclusions are then outlined as to the remarkable capacity of the circus arts to drive socio-territorial innovation, both by upgrading the urban public space and through the social inclusion of children and youths at risk.

Key words: Social innovation, socio-territorial innovation, socially creative milieux, city, circus.

Résumé - Le Cirque eST ARRIVÉ! Des Possibilités D'INNOVATION SOCIALE ET TERRITORIALE. On discute en quelle mesure les arts, et le cirque en particulier, peuvent contribuer au développement territorial, en favorisant l'innovation sociale. La diversité tolérante, la participation et la mémoire collective qui caractérisent quartiers, villes et régions, se retrouvent dans les milieux artistiques et surtout dans le cirque. Le cas du "Chapiteau", à Lisbonne, illustre bien cette idée. Ses multiples activités allient, comme chacun sait, les arts du cirque à la récupération sociale. Cependant il paraît avoir quelque difficulté à réaliser le saut quantitatif qui lui permettrait d'élargir son échelle d'action et d'améliorer son degré de qualification. D'une façon plus générale, les arts du cirque montrent une remarquable capacité d'innovation socioterritoriale, en permettant de valoriser l'espace public et de mieux intégrer socialement des enfants et adolescents en difficulté.

Mots-clés: Innovation sociale, innovation socio-territoriale, milieux socialement créatifs, ville, cirque.

"Circo tem, antes de mais, o fascínio do espaço circular, onde a festa é envolvente e envolvida; onde os espectadores se vêem entre si através do espectáculo e onde todos comunicam, porque todos se referem ao ponto central que geométrica e sensorialmente nos liga."

JoÃo DOS SANTOS, 1981:181

\section{INTRODUÇÃO}

Os meios artísticos, ou seja, aqueles onde as artes são a principal forma de expressão e de comunicação, são, à partida, criativos. A arte só é verdadeiramente reconhecida quando se afasta da reprodução e faz emergir um novo objecto. Pode ser um corte com o passado, com as expressões instituídas, mas pode ser também uma reconstrução ou uma reinvenção do passado. É invariavelmente um novo ponto de vista - com ou sem expressão material - com "ingredientes" que impulsionam a mudança e que combatem a inércia.

A produção artística tem sido geralmente associada às elites, pelo menos aquela que é mais reconhecida do ponto de vista social e economicamente mais valorizada. A beautification da realidade e do quotidiano são preocupações que surgem associadas aos grupos sociais e aos territórios mais favorecidos. As 
últimas décadas têm observado, porém, mudanças significativas neste campo. No mundo ocidental, a democratização da cultura e da arte tem sido uma preocupação constante das políticas de desenvolvimento social e territorial. Com esse objectivo, os investimentos em bibliotecas, museus, centros culturais ou escolas de arte têm-se multiplicado.

Paralelamente, a arte é cada vez mais uma mercadoria. Nas sociedades pós-industriais, ou simplesmente pós-modernas (porque também existe uma pós-ruralidade), a produção cultural parece sobrepor-se à produção industrial. Pode mesmo falar-se do entrosamento dos dois tipos de produção. A estética dos produtos industriais, a importância da forma em detrimento da função, ou a importância do prazer associado aos objectos ou às experiências são aspectos que ganham cada vez mais relevo.

A própria produção artística passa frequentemente pelos critérios associados à competitividade. $\mathrm{O}$ debate sobre a cidade criativa é um dos melhores exemplos da visão mercantil da cultura e das artes. De facto, Richard Florida $(2002,2008)$ ou Charles Landry (2000) defendem que a atracção de gente criativa é a principal condição para captar investimento. Na sua opinião, o capital segue as rotas traçadas pela classe criativa!

Nesta cidade criativa, a cultura e as artes assumem um papel principal (Hall, 2000). Por um lado, a oferta cultural é um factor de atracção importante, seja por via da arquitectura e do espaço público que configuram as condições de habitação da classe criativa, seja através dos espectáculos, das exposições ou de outros eventos que preenchem os tempos de lazer desse grupo. Por outro lado, os artistas fazem parte da classe criativa. Tanto os artistas num sentido mais tradicional - pintores, actores, músicos, etc. - como os mais contemporâneos como os designers, produtores de vídeo, criadores de mensagens publicitárias e outros.

O grande problema da cidade criativa é não ser normalmente uma cidade inclusiva. Com frequência, a construção de uma grande sala de espectáculos, ou de um museu no centro da cidade, leva à expulsão dos antigos residentes. Por outro lado, as operações de regeneração urbana associadas à oferta imobiliária dirigida à classe criativa correspondem normalmente a processos de gentrificação (Ley, 2003; Moulaert et al., 2004).

Julgamos, no entanto, que a cidade criativa não é fatalmente exclusiva. Pode ser uma cidade inclusiva e solidária. Ou seja, é possível falar de cidades socialmente criativas (Gertler, 2004; Scott, 2006).

O circo é uma expressão artística com potencialidades singulares para participar na construção de cidades socialmente criativas. Não tem uma história ligada às elites. Até há poucas décadas, expressava-se frequentemente no espaço público (a feira) através de pessoas que usavam os seus dotes artísticos para sobreviverem. Mas, voltaremos ao circo mais tarde. 


\section{MEIOS E LUGARES SOCIALMENTE CRIATIVOS}

Um meio socialmente criativo não é apenas aquele que impulsiona a expressão criativa mas também o que promove a inovação social. A inovação social é aqui entendida como uma resposta nova para necessidades sociais não satisfeitas, ou mesmo não reconhecidas. Essas respostas são diversas consoante as necessidades em causa mas têm em comum a intenção de promover a inclusão social através da transformação das relações sociais (configuradas a partir do trabalho, do género, da etnia, etc.), nomeadamente pelo empowerment e pela valorização do capital social colectivo nas comunidades mais frágeis e vulneráveis (André e Abreu, 2006; Martinelli et al., 2003; Klein e Harrisson, 2007).

Nesta perspectiva, a inovação social está associada a iniciativas que escapam à ordem estabelecida, na medida em que representam uma nova forma de pensar ou de fazer algo e uma mudança social qualitativa, uma alternativa - ou até mesmo uma ruptura - face às práticas usuais ou convencionais. "L'innovation affronte l'institué, c'est-à dire qu'elle défait la tradition, elle dépasse la routine et elle défie les contraintes" (Comeau, 2004: 37)

O conceito de milieu innovateur, desenvolvido por Aydalot e pelo Groupe de Recherche Européen sur les Milieux Innovateurs (GREMI) a partir dos anos 80 (Aydalot, 1986), pretende essencialmente dar conta de como é que os lugares promovem ou dificultam a inovação. Contudo, a transposição do conceito de 'milieu innovateur' para meio socialmente inovador, ou criativo, não é linear. Embora se encontrem pontos de convergência, sobretudo em termos dos recursos que incentivam a inovação e a criatividade, muitos outros parâmetros são distintos.

A noção de plasticidade, adoptada da física, pode ajudar-nos a compreender a natureza e as dinâmicas dos meios inovadores, em geral, e dos socialmente criativos, em particular. "La plasticité désigne la capacité qu'ont certains composants à s'in-former (recevoir une forme) et à se dé-former, tout en gardant unité et cohérence. La plasticité est donc une condition nécessaire pour que la vie apparaisse, se maintienne et puisse évoluer." (Entrevista de Dominique Lambert à Radio France Internationale, a propósito do livro Comment les pattes viennent au serpent. Essai sur l'étonnante plasticité du vivant, Dominique Lambert, René Rezsöhazy, Editions Flammarion, 2004).

Se se transpuser este conceito para os meios sócio-territoriais, a plasticidade significa que os lugares onde a criatividade vai germinar devem ser suficientemente flexíveis e, ao mesmo tempo, suficientemente organizados para que possam sofrer transformações culturais, económicas e sociais sem perderem a sua identidade (André et al., no prelo).

Os meios socialmente criativos parecem reunir quatro características principais: diversidade sócio-cultural ligada à abertura ao exterior; tolerância, na medida em que permitem o risco; democraticidade, correspondente à participação activa dos cidadãos; memória colectiva, na medida em que assegura a resiliência do meio. A diversidade potencia o contacto com o novo no sentido da 
alteridade - novos-outros produtos, novos-outros saberes, novos-outros valores - mas pode também produzir fragmentação e isolamento; a diversidade promove a inovação na medida em que se estabelecem pontes e fluxos entre aquilo que é diferente. A tolerância é uma condição necessária à possibilidade de errar - a inovação é uma tarefa arriscada - e um meio não pode ser criativo e inovador se penalizar os eventuais insucessos de uma iniciativa arriscada, ou seja, se for demasiado hierarquizado, normativo ou rígido. A democraticidade implica ter possibilidade e capacidade de decisão, ou seja, ter acesso à informação e ao conhecimento necessários à escolha e à identificação de soluções adequadas, ser socialmente reconhecida a decisão e ser exigida a responsabilização de quem decide (André e Abreu, 2006). O diálogo faz emergir a inovação e alimenta a criatividade. A memória colectiva pode prevenir a fragmentação potencialmente associada à inovação como efeito adverso. Na medida em que sustenta a identidade da comunidade e o sentido de pertença das pessoas, é um factor importante de resiliência, de resistência ao choque da mudança. Contudo, a memória colectiva, porque comporta o "peso do passado", pode ser também um factor de inércia e de resistência às estratégias criativas.

A ligação da inovação social a um determinado meio capaz de a promover e, por outro lado, a capacidade das mudanças no território desencadearem novas respostas e novas relações sociais remetem para a ideia de inovação sócio-territorial, conceito que atribui ao território um papel activo nos processos de inovação social.

\section{O CIRCO NA CONSTRUÇÃO DE MEIOS SOCIALMENTE CRIATIVOS}

As artes, no seu conjunto, assumem um papel relevante como estímulo da inovação social, especialmente na medida em que inspiram estratégias sociais criativas, ou seja, que estimulam as comunidades ou os grupos mais desfavorecidos no sentido de encontrarem novas respostas, alterando as condições e reconstruindo as relações sociais que provocam a sua vulnerabilidade. Nas sociedades, como as europeias ou as norte americanas, onde o sentido da transcendência se foi perdendo (quer pela erosão da religião quer pela falência das grandes ideologias que marcaram os séculos XIX e XX), a arte preenche, de alguma forma, esse "vazio" (Ruby, 2002, 2003). É uma via de antecipação do futuro. "Some artists express in their work feelings or codes that forecast the future or that indicate symbolically that the present is no longer viable." (Smiers, 2005: 9).

Contudo, as artes não são apenas uma fonte de inspiração. São expressões facilitadoras da comunicação entre diferentes culturas, na medida em que transmitem significados que a linguagem comum tem dificuldade em revelar. Por outro lado, permitem transmitir as emoções e os sentimentos mais profundos dos seres humanos. Por exemplo, o terror que a Guernica de Picasso transmite dificilmente se poderia expressar de outra forma, sendo facilmente captado por 
pessoas com pertenças culturais diversas. A utilização de metáforas faz transcender o óbvio e comunicar para além do discurso comum (Ruby, 2002, 2003; André e Abreu, no prelo).

A estetização do quotidiano (Smiers, 2005; Ley, 2003; Cachinho, 2006) tem vindo a afirmar-se cada vez mais nas sociedades ocidentais. A pós-modernidade atribui à estética a importância que a modernidade conferiu à função e, neste contexto, as artes assumem uma importância crescente na vida das pessoas e das comunidades.

Os argumentos referidos nos parágrafos anteriores aplicam-se também ao circo. Importa, no entanto, ampliar a reflexão, na medida em que as artes circenses comportam particularidades que lhes conferem um papel específico e marcante no quadro das estratégias sociais criativas.

Com raízes muito antigas, entre as quais se salientam o circo romano e os saltimbancos das feiras medievais, o circo moderno inicia-se em Inglaterra, no século XVIII, com o teatro equestre, onde actuavam não só cavaleiros, mas também acrobatas e palhaços. Nos países europeus onde as artes equestres eram mais desenvolvidas e, ao mesmo tempo, naqueles onde se realizavam as grandes feiras com uma grande panóplia de divertimentos (França, Alemanha, Itália, Rússia), rapidamente surgiram companhias de circo cujos espectáculos tinham uma procura muito significativa. Durante o século XIX, a procura era tão grande - particularmente em França - que foram construídos edifícios especificamente destinados às artes circenses. $\mathrm{O}$ mais emblemático era o Cirque Olympique, dos Irmãos Franconi, em Paris (Jacob, 2002).

O desenvolvimento do circo nos Estados Unidos da América, a partir da $3^{\mathrm{a}}$ década do século XIX, vai introduzir uma inovação crucial - o chapiteau e a consequente possibilidade de itinerância. Esta mudança possibilita a captação de um público muito mais vasto, o que vai permitir algum fausto para "abrilhantar" os espectáculos. Por outro lado, o nomadismo gera uma forte coesão interna nas companhias. "Les arts du cirque sont non seulement creatifs, mais également inclusifs. Sous la toile du chapiteau, un néophite réalise que rien n'est possible sans les autres, que le cirque est une aventure fondamentalement collective. Autour de la piste, il est question de famille élargie et tous sont des enfants du voyage, des saltimbanques" (En Piste, 2005: 15).

$\mathrm{O}$ circo atravessou uma fase difícil a partir dos anos 60 do século XX, associada sobretudo às novas preocupações com as condições de vida dos animais, em particular com as espécies protegidas como algumas das que integravam os espectáculos de circo (focas ou chimpanzés). Mas a crise deveu-se também às barreiras que a organização espacial do chapiteau põe à inovação tecnológica. A presença de público quase a toda a volta da pista não permite, por exemplo, a utilização de projecções vídeo ou a montagem de equipamentos complexos que exigem uma infraestrutura "escondida" (Camus, 2004).

Como resposta à crise, o circo contemporâneo ou 'novo circo' emergiu no final dos anos 70, manifestando rupturas significativas com o circo tradicional, nomeadamente: o desaparecimento dos animais selvagens; a (re)organização do 
espaço dentro do chapiteau; a introdução de um fio condutor das várias exibições através de uma coreografia integradora; a adopção de novas estéticas, particularmente ao nível da música e das cores (Camus, 2004; Jacob, 2002).

Apesar destas mudanças, o circo vai manter, em larga medida, a itinerância e o sentido de comunidade, características que lhe podem conferir um papel importante na cidade socialmente criativa. Por outro lado, a origem popular do circo aproxima-o, enquanto expressão artística, das populações mais desfavorecidas.

Outro aspecto que confere às artes circenses um papel decisivo como instrumento de estratégias socialmente criativas é a diversidade das expressões e a cooperação entre os vários protagonistas. Palhaços, acrobatas, mágicos, malabaristas, músicos e muitos outros que trabalham na pista ou na sombra constroem colectivamente o espectáculo. No 'novo circo', contam uma história em conjunto utilizando linguagens e discursos diversos.

A inovação social ligada ao circo faz emergir inevitavelmente o caso do Cirque du Soleil, um targeted growth and committed cirque (www.cirque dusoleil.com, acedido em 15 Setembro 2008). Nos anos 80, um grupo de jovens do Québec procurou nas artes circenses um modo de sobrevivência. Apoiados por autoridades públicas especialmente "protectoras" e inspirados pelos "ventos" de Woodstock e pela vontade de mudar o mundo partilhada pela juventude dos anos 60 , transformaram acrobacias e magias tradicionais num circo reinventado ${ }^{2}$ que tiveram a oportunidade de apresentar em todo o Québec em 1984, no quadro das comemorações dos 450 anos da chegada de Jacques Cartier ao Canadá. Agitando a bandeira da inovação e de uma conduta politicamente correcta, esse grupo de jovens, e especialmente Guy Laliberté, o mais empreendedor e audacioso, criou, em menos de 20 anos uma das mais reconhecidas empresas multinacionais no campo das artes (Beaunoyer, 2005).

O percurso de sucessos consecutivos do Cirque du Soleil não o impediram, contudo, de manter um compromisso social forte em termos de inclusão social. Através do Cirque du Monde e de múltiplas parcerias espalhadas pelo mundo, a imagem mágica e espectacular do Cirque du Soleil tem contribuído decisivamente para o desenvolvimento de muitas estratégias sociais criativas. No caso do seu lugar de origem, a acção vai mais longe através da implicação directa num mega-projecto de regeneração urbana num espaço periférico e problemático de Montreal - o bairro de Saint-Michel (TOHU, 2008).

Mas, qual é afinal a magia do circo no campo da inovação social, em geral, e da inovação sócio-territorial, em particular? As ligações entre circo e território são várias e manifestam-se a várias escalas. Ao nível nacional e internacional, a itinerância do circo e as rotas que traça para mobilizar o seu público. Na cidade, o circo instala-se num espaço público e estabelece inevitavelmente uma relação

2 Um dos primeiros espectáculos do Cirque du Soleil chamou-se precisamente "Cirque Réinvinté". 
de vizinhança efémera mas intensa. No chapiteau e em seu redor, a organização do espaço é um factor decisivo para o sucesso da companhia. É necessário não só conjugar uma grande diversidade de expressões artísticas num mesmo espaço, mas também conjugar os espaços de trabalho, de residência, de aprendizagem ou de lazer.

Para discutir a relação do circo com a inovação social, importa - antes de passarmos para o caso específico do Chapitô, em Lisboa - retomar algumas ideias apontadas anteriormente. Já referimos que os meios socialmente criativos são aqueles que conjugam diversidade, tolerância, participação e memória colectiva. O circo associa bastante bem essas quatro características: (i) pluralidade de expressões artística s, diversidade de origens geográficas dos artistas, convívio de diferentes gerações; (ii) tolerância associada ao risco omnipresente nas artes circenses; (iii) participação de todos - artistas e outros trabalhadores - para produzir uma obra conjunta que depende de todos e de cada um; (iv) memória colectiva da comunidade/companhia que atravessa frequentemente diversas gerações, projectando-se para além dos percursos individuais.

Esta perspectiva do circo como veículo de inovação sócio-territorial vai ser o fio condutor da apresentação do Chapitô.

\section{O CHAPITÔ EM LISBOA}

Sempre que se fala do Chapitô, vem-nos à memória a magnífica vista do estuário do Tejo recortado pelas construções mais antigas da cidade. Um privilégio para todos os que lá trabalham e para os que por lá passam. A localização na Costa do Castelo, em Lisboa, tem esta mais valia que oferece aos seus públicos temporada após temporada. O rio, o casario, a luz, ou as luzes da cidade são parte do cenário das artes do espectáculo, com especial relevância para as artes circenses que aqui se aprendem e mostram. Instalado neste bairro histórico, desde 1986, o Chapitô afirmou aqui o seu papel de associação recreativa e cultural, que também é ONG para o desenvolvimento, com estatuto de Instituição Particular de Solidariedade Social (IPSS). O trabalho desenvolvido ao longo de mais de duas décadas conquistou um lugar de referência na cidade pela reconhecida acção na produção cultural e artística, bem como no campo da inclusão social. A reflexão que aqui se apresenta é acompanhada de excertos de entrevistas realizadas a colaboradores e antigos alunos do Chapitô ${ }^{3}$, especialmente aqueles que deixaram de estar em situação de risco e construíram até um percurso de sucesso. São sobretudo esses que nos ajudam a compreender as artes do circo enquanto veículo de inovação social.

3 Estas vozes que vão surgindo ao longo do texto são identificadas com nomes fictícios. Não pretendemos dar conta das várias opiniões pessoais, mas utilizar os discursos para ilustrar a reflexão que efectuámos sobre o Chapitô. 


\section{O ESSENCIAL DO CHAPITÔ}

\section{Estatutos oficiais}

IPSS/ Instituição Particular de Solidariedade Social, ONG’D/ Organização Não Governamental para o Desenvolvimento, "Utilidade Pública", "Manifesto Interesse Cultural".

\section{Área Social}

Animação sócio-formativa: Centros Educativos da Bela Vista e Navarro de Paiva, trabalho com jovens até aos 18 anos (protocolo assinado com o Instituto de Reinserção Social em 1987). Casa do Castelo: Lar de transição, apoio psicossocial a jovens com mais de 18 anos que enfrentam dificuldades no início do seu projecto de vida (capacidade para 6 jovens). Centro de Acolhimento João dos Santos: Espaço educativo e lazer para crianças até aos

12 anos acolhe filhos de pessoas do bairro, de colaboradores e de jovens artistas.

\section{Escola Profissional de Artes e Ofícios do Espectáculo (EPAOE)}

Funciona desde 1991 - Recebe alunos com o $9^{\circ}$ ano em 2 cursos de nível 3 (equivalente ao $12^{\circ}$ ano), ultrapassou os 300 diplomados em 2006. Para amadores, em horário pós-laboral, existem Cursos de Fim de Tarde, orientados por profissionais da casa: capoeira, malabarismo, sapateado, caracterização, expressão dramática, técnicas circenses e ateliers para crianças.

\section{Companhia do Chapitô}

Criada em 1996, define-se como teatro do gesto/teatro físico. A companhia possui no seu repertório mais de duas dezenas de criações originais onde se incluem espectáculos para a infância. A actividade da companhia é uma das faces de maior visibilidade da instituição e a sua política de itinerância tem divulgado os seus espectáculos nacional e internacionalmente.

As múltiplas actividades do Chapitô (www.chapito.org acedido em 11 de Julho de 2008) surgem invariavelmente associadas a uma liderança forte, uma personalidade que inspira admiração, uma figura impulsionadora. Falamos de Teresa Ricou que, no início dos anos 80, ainda a partir da sua casa do Bairro Alto, criou a Colectividade Recreativa e Cultural de Santa Catarina que entretanto expandiu e consolidou no espaço da Costa do Castelo. A sua liderança, que leva mais de 20 anos, continua hoje a marcar a intervenção social e cultural do Chapitô na cidade, sendo indissociável do seu reconhecimento público.

A partir da sua formação e experiência em França, Teresa Ricou desenvolveu uma carreira de artista de circo, tornando-se conhecida como Teté, a primeira mulher-palhaço portuguesa. Ainda no Bairro Alto, nos anos 70, começou um trabalho com crianças de rua que aliava a componente artística e social, e possibilitou colaborações designadamente com a Santa Casa da Misericórdia de Lisboa e o Ministério da Justiça. A perspectiva de fazer das artes do circo uma forma de inclusão, inaugurou em Portugal uma nova abordagem do problema da exclusão e marginalização de crianças e de jovens. No âmbito da reinserção social de adolescentes, as propostas de actividades são geralmente mais convencionais podendo incluir desde a serralharia à panificação. Daí que não tenha sido tarefa fácil convencer os serviços responsáveis do Ministério da Justiça acerca do potencial formativo das artes circenses. O perfil de liderança e o extenso capital social de Teresa Ricou foram decisivos e os resultados não se fizeram esperar. 
"Desde criança que fazia rir os outros, aqui tornei-me clown." (Miguel)

"Na escola primária, ralhavam-me porque fazia coisas perigosas, agora sou professor de acrobacia." (Pedro)

A determinação e as experiências desenvolvidas abriram portas ao posterior reconhecimento pelas entidades públicas com tutela na área da protecção de menores. O protocolo com os serviços tutelares de menores (Ministério da Justiça), estabelecido em 1986, possibilitou a concessão do edifício da Costa Castelo, antigas instalações de uma tutoria de mulheres, e a sua posterior recuperação e adaptação progressiva a um programa de actividades sempre renovado. $\mathrm{O}$ combate à exclusão social através da cultura e das artes, objectivo primordial do Chapitô, ganhou com este espaço uma dinâmica que naturalmente escapa ao observador diletante. A ideia segundo a qual é possível ter uma vida digna sendo artista de circo e que se pode caminhar nessa aprendizagem com entusiasmo e ganhos de auto-estima fez o seu caminho dentro e fora do Chapitô.

A acção social do Chapitô está presente em dois centros educativos (Direcção Geral de Reinserção Social) na cidade de Lisboa - Bela Vista (Bairro da Graça) e Navarro de Paiva (em S. Domingos de Benfica) - que acolhem crianças e jovens do sexo masculino a cumprir medidas de internamento. A acção nos centros educativos concentra-se na animação de ateliers de frequência facultativa, possibilitando diversas actividades: circo, capoeira, música, "faz-tudo", jogos, histórias, teatro, horta e outras. A partir dos ateliers organizam-se actividades lúdicas e artísticas que apelam à expressão individual e colectiva. Encorajar aprendizagens dando prioridade à comunicação é o lema das equipas de animadores que dispõem de uma coordenação e de uma retaguarda de reflexão e formação. As apresentações públicas dão sentido e visibilidade ao trabalho desenvolvido e podem ocorrer nos próprios centros, no espaço do Chapitô ou noutros locais. A experiência de 26 anos na acção social e no contacto com as instituições de reinserção social sempre exigiu elevada perseverança. Esta atitude tem sido indispensável face às sucessivas alterações de enquadramento legal e à constante adaptação aos condicionalismos que envolvem crianças e jovens em risco. Trata-se de afirmar um projecto assente na capacidade de incluir crianças e jovens frequentemente envolvidos em trajectos sem projecto, com enorme probabilidade de conduzirem à marginalidade.

\footnotetext{
"Para mim existem vários chapitôs. Existe a escola EPAOE a qual chamamos todos Chapitô mas também existe o "Coas" (acção social) que também está ligado ao Chapitô e para mim a localização geográfica do Chapitô "escola" não tem muita importância, talvez seja mesmo uma menos valia pois por vezes desconcentra os alunos que pensam estar sempre de férias, mas a nível do "Côas" talvez tenha mais importância pois muitos dos miúdos que fazem parte desse projecto saem de bairros dali próximos." (Rui)
}

Ainda no campo da inclusão, existe também a "Casa do Castelo" que acolhe jovens com mais de 18 anos que enfrentam dificuldades e precisam de apoio 
e alojamento. Outros jovens em risco que precisam de ajuda no seu processo de autonomização também podem encontrar apoio psicossocial pontual, dispondo de uma equipa de apoio ao desenvolvimento de um projecto de vida pessoal. Funciona igualmente no edifício o "Centro de Acolhimento João dos Santos" para crianças dos 8 meses aos 12 anos, residentes no bairro ou filhos de funcionários. A equipa educativa deste centro, que recebeu o nome de um dos maiores psico-pedagogos portugueses do século XX, tem como linha orientadora o trabalho comunitário, ou seja, a ponte entre o Chapitô e a comunidade local.

Em 1990, aproveitando a promulgação pelo Ministério da Educação do diploma que criou o ensino e as escolas profissionais, o Chapitô fundou a Escola Profissional de Artes e Ofícios do Espectáculo (EPAOE). A escola recebe alunos com o $9^{\circ}$ ano (ensino básico) e oferece cursos secundários, que conferem equivalência ao $12^{\circ}$ ano. Com a entrada de 25 alunos (aproximadamente) em cada curso, estão em funcionamento: o curso de Interpretação e Animação Circenses (IAC) e o curso de Cenografia, Figurinos e Adereços (CenFA). À semelhança do que se passa com muitas outras escolas profissionais, uma grande parte dos alunos teve percursos escolares problemáticos no ensino básico. Embora nos anos mais recentes a situação tenda a mudar, o ensino secundário profissional não surge, na maioria dos casos, como uma opção, mas como solução de recurso.

\footnotetext{
"Abandonei a escola várias vezes para trabalhar nas obras com o meu pai por exemplo e noutros trabalhos como montador de aparelhos de ar condicionado. Tive épocas em que trabalhava e estudava, fiz até ao $10^{\circ}$ ano, mas não estava a dar... A escola onde estava organizou uma visita aqui ao Chapitô e disseram-me que eu tentasse fazer as provas de acesso para vir para aqui. No início, resisti. Basicamente porque aqui não conhecia ninguém, era escurinho e não tinha aqui os amigos (...). Mas, a adaptação foi rápida. Isto é uma escola mas é sobretudo uma casa... falamos abertamente dos nossos problemas..." (Dinis)

"Foi a melhor coisa que me aconteceu na vida (ir para o Chapitô)... aquelas pessoas são especiais... eu dei-me de corpo e alma! Agora o meu objectivo é estudar para os exames nacionais e entrar na Faculdade de Letras. (Artes do Espectáculo)" (Miguel)

"Graças ao Chapitô passei a ser um aluno interessado... comecei a existir como pessoa... com o meu trabalho fui adquirindo o respeito e por vezes a admiração dos outros." (Rui)
}

Os depoimentos dos alunos que passaram pela escola do Chapitô são elucidativos da comunidade de afectos que atravessam o ambiente e as experiências que aí se vivem. A actividade da escola envolve a colaboração com circos profissionais e outras companhias ligadas às artes do palco, quer para acolher os estagiários, quer para proporcionar aos alunos o contacto com o desenvolvimento de projectos artísticos inovadores, designadamente no âmbito do 'novo circo'.

"Fiz estágio de clown na Escola de Circo Carampa em Madrid... É uma escola que puxa muito por nós, sobretudo no malabarismo e no tecido. Mas o clown é uma coisa que se aprende mais por nós... não é uma técnica é um trabalho." (Miguel) 


\begin{abstract}
“Trabalhei na companhia de dança Olga Roriz em Lisboa. Quem sai daqui geralmente não vai para circos tradicionais. As oportunidades não são muitas. Ou se vai para uma escola fora do país ou então faz animações que é também o que eu faço." (Luís)

"Estou a trabalhar na Companhia de Teatro Artistas Unidos." (Cátia)
\end{abstract}

Ainda na área de formação, o Chapitô oferece cursos de fim de tarde abertos a todo o público: capoeira, malabarismo, sapateado, expressão dramática e outros. A oferta completa-se com workshops específicos para as várias faixas etárias e ateliers para crianças. A formação de novos públicos merece atenção especial através da criação de espectáculos para crianças nas tardes de sábado e domingo. Esta diversidade de actividades parece ajudar a multiplicar as oportunidades de trabalho e naturalmente a enriquecer a oferta cultural.

A sustentabilidade financeira do Chapitô reside em grande medida na companhia de teatro-circo e na animação. A companhia do Chapitô foi criada em 1996 e define-se como teatro do gesto/teatro físico ${ }^{4}$. No seu repertório conta com 25 criações originais que apresentou não apenas em Portugal, como em muitos países dentro e fora da Europa, sobretudo através da participação em festivais. As produções Chapitô fazem também animações e espectáculos nos mais diversos lugares, desde empresas e espaços públicos a festas particulares. Encontra-se aqui uma das principais fontes de financiamento das acções na área social para além dos apoios das entidades oficiais.

Dada a ausência em Portugal de formação superior nas artes do circo, alguns alunos têm prosseguido a sua formação noutros países, especializando-se nas mais diversas disciplinas. Um exemplo de um percurso bem sucedido é o de João Paulo Santos. Depois de se especializar em França no "mastro chinês" desenvolveu uma carreira de criação de espectáculos de novo circo, que têm sido apresentados em palcos estrangeiros e portugueses com enorme sucesso.

"O meu trajecto formativo no Chapitô foi muito interessante pois mudou o rumo da minha vida, foi graças ao Chapitô que, pouco a pouco, percebi que através do trabalho se conseguia algo, de repente passei a ser um aluno aplicado e com vontade de perceber tudo. A nível relacional também foi muito importante pois foi ali que comecei a existir como pessoa dentro da sociedade, foi através do meu trabalho que também fui adquirindo o respeito e por vezes a admiração dos outros, tudo isto foi fazendo de mim alguém com vontade e capacidade de acreditar nos seus sonhos, o que era impossível alguns anos atrás." (João Paulo Santos)

No entanto, depois de concluído o curso, os percursos são muito diversos: desde a especialização fora do país ou nas escolas nacionais (os Conservatórios), ao trabalho na televisão, no cinema e em companhias de teatro e dança. Nos bastidores, nos palcos ou nos ecrãs muitos dos alunos formados no Chapitô têm

4 À semelhança, por exemplo, do Cirque du Soleil ou do grupo catalão La Fura dels Baus. 
vindo a encontrar lugar no mundo do espectáculo, mesmo se essa ligação é ocasional através, por exemplo, da participação na animação de eventos. Nas artes circenses, apesar de se registar o aparecimento de alguns grupos e parelhas, a produção é escassa e a formação requer maior qualificação.

Importa contudo salientar que, sendo uma instituição local, o Chapitô tem construído uma rede de relações nacionais e internacionais significativa, que possibilitam, de alguma forma, a ligação multi-escalar.

\section{REDE DE PARCERIAS DO CHAPITÔ}

\section{Parcerias Nacionais}

- Ministério da Educação

- Ministério da Cultura (Instituto das Artes)

- Ministério da Justiça (Direcção Geral de Reinserção Social)

- Ministério do Trabalho e da Solidariedade (Centro Regional de Segurança Social)

- Secretaria de Estado da Juventude (Instituto Português da Juventude)

- ANESPO - Associação Nacional das Escolas Profissionais

- Associação Castelo Colina Cultural

- CEJ - Centro de Estudos Judiciários

- EGEAC - Empresa de Gestão de Equipamentos e Animação Cultural

- ISPA - Instituto Superior de Psicologia Aplicada

- ISSS-COOP - Instituto Superior de Serviço Social

- Moinho da Juventude

- Plataforma Nacional das ONGD

- Rede dos Centros Culturais Portugueses

Parcerias Internacionais

- Associacion de Malabaristas de Madrid - Espanha

- Banlieux d'Europe

- Centre National des Arts du Cirque - Chalons sur Marne, França

- Circustheater Ellebog - Amesterdão, Holanda

- Circus Space - Londres, Inglaterra

- Creative Corporation - Berlim, Alemanha

- EFECOT - European Federation for Education of the Children of the Occupacional Travellers - Bruxelas, Bélgica

- FEDEC - Federation Européenne des Écoles de Cirque

- European Cultural Foundation

- Opgang 2 - Dinamarca

- Peuple et Culture - Montpellier, França

- Soros Center For The Arts - Sofia, Bulgária

Fonte: Site do Chapitô - http://chapito.org (acedido em 13 de Fevereiro de 2009)

"Um dos aspectos mais importantes é o facto de o Chapitô ser a única escola que ensina as artes circenses o que faz também com que o nível técnico seja muito baixo devido à falta de concorrência. Em França, por exemplo, existem mais de 300 escolas onde se pode aprender a fazer circo, mas, de facto, do ponto de vista curricular é a única escola a fazê-lo (...) apesar de tudo, o Chapitô é uma escola com algumas lacunas nomeadamente em termos de espaço. A falta de grandes espaços priva os alunos de outras disciplinas circenses indispensáveis, como, por exemplo, a cama elástica.” (Rui) 


\begin{abstract}
"Já tive planos para ir para o Cirque du Soleil, mas acabei por desistir. Nós aqui temos uma preparação boa porque também é psicológica, mas ao nível das técnicas estamos longe do que se faz lá fora. Já fiz provas para uma escola de circo em Londres mas depois não consegui financiamento nem bolsa e tive de desistir. Estão lá cinco pessoas da minha turma, mas que foram com recursos da família. Foi também isso que me fez mudar de planos e ir mais para o teatro..." (Miguel)
\end{abstract}

A presença do Chapitô na cidade, através das suas actividades e da dinâmica de participação nas suas redes culturais, é um dado adquirido e reconhecido. Contudo, parece ainda faltar no âmbito das artes do circo e em particular do novo circo, uma valência que possa vir a especializar e aprofundar a formação e a divulgação. Nesse sentido, o futuro pode passar pelo "Chapitô-rio", projecto que parece ganhar forma nas docas de Santos. Este projecto vem sendo acalentado há anos mas tarda em concretizar-se. Seria um equipamento cultural do maior interesse para Lisboa, possibilitando o desenvolvimento de uma arte que tem vindo a afirmar-se com grande êxito em muitas cidades pelo mundo fora. Pode também residir aí uma ocasião da cidade participar, através do novo circo, em redes culturais mais amplas, dando maior espaço e visibilidade à criação artística nacional e colocando Lisboa no mapa global das artes do circo contemporâneas. Terá chegado o tempo de um Chapitô para o século XXI?

\title{
V. REFLEXÕES FINAIS
}

A análise do Chapitô e das suas potencialidades para participar numa cidade criativa e inclusiva pode inspirar futuras pesquisas. Salientamos dois aspectos que nos parecem particularmente interessantes.

O primeiro relaciona-se com a importância da líder carismática. Como em muitas outras instituições, e particularmente naquelas que surgem como casos de referência, o papel individual sobrepõe-se ao protagonismo colectivo. A capacidade de liderança, ou seja, a associação de visão (no sentido visionário), capital social, autoridade, entusiasmo e determinação emerge como uma condição crucial para o desenvolvimento das iniciativas mais inovadoras, transforma projectos em utopias realizáveis. Mas este talento tem também um reverso. São raras as vezes em que os líderes carismáticos passam o testemunho a outros, assegurando a sustentabilidade das acções para além da sua presença. Normalmente, em determinado momento do percurso das instituições mais inovadoras, surge o impasse: sem o líder não haveria passado e com a permanência do líder o futuro pode estar comprometido.

O segundo liga-se à escala de acção. Instituições como o Chapitô destacamse ao nível local como motores importantes de inovação e de inspiração. Esta escala é uma condição para o sucesso, ou é possível desenvolver iniciativas análogas ao nível regional ou mesmo nacional? As "vozes" que surgiram neste artigo mostram como as relações de proximidade são determinantes para aliar 
criatividade e inclusão social. Ainda assim, julgamos que a questão das escalas é pertinente, especialmente numa óptica multi-escalar. A ligação do bairro ao resto do mundo é actualmente possível, fácil e potencialmente inclusiva. Por outro lado, as fronteiras, o isolamento e a autarcia são factores de inércia e barreiras à inovação. No caso do Chapitô, a escola profissional, sobretudo através dos estágios, as digressões da companhia e a vinda de professores e artistas convidados estabelecem uma ligação directa, embora nem sempre muito intensa, do local, do Bairro do Castelo à Área Metropolitana de Lisboa (onde reside a maioria dos alunos) ao País e ao Mundo.

Numa leitura mais ampla, consideramos que as artes circenses denotam uma capacidade assinalável para impulsionarem a inovação sócio-territorial.

Por um lado, através da (re)valorização do espaço público urbano. Por ser uma arte que nasceu e cresceu na rua, o circo lida bem com os espaços colectivos (como refere João dos Santos na frase que dá início a este artigo), conferindo-lhes brilho e alegria. Por outro lado, a expressão artística circense mostra-se especialmente adequada enquanto veículo de inclusão social. Promove a auto-estima através do reconhecimento público imediato (à semelhança das outras artes do palco). Acolhe todos aqueles que participam na produção numa comunidade de afectos, de cooperação e de inter-ajuda. Oferece uma grande diversidade de oportunidades de expressão artística, favorecendo as várias formas de comunicação e especialmente a corporal.

Podemos assim considerar que o circo pode ser um elemento central da cidade socialmente criativa.

\section{BIBLIOGRAFIA}

André I, Abreu A (2006) Dimensões e espaços da inovação social. Finisterra - Revista Portuguesa de Geografia, XLI(81): 121-141.

André I, Abreu A (no prelo) Social creativity and post-rural places: the case of Montemor-o-Novo, Portugal. Canadian Journal of Regional Science/Revue Canadienne des Sciences Régionales, special issue on Social Innovation and Territorial Development.

André I, Brito Henriques E, Malheiros J (no prelo) Inclusive places, arts and socially creative milieux. In MacCallum D, Moulaert F, Hillier J, Vicari S (eds.) Social Innovation and Territorial Development. Ashgate, London.

Aydalot P (1986) Milieux innovateurs en Europe. GREMI, Paris.

Beaunoyer J (2005) Dans les coulisses du Cirque du Soleil. Québec Amérique, Montreal.

Cachinho H (2006) Consumactor: da condição do indivíduo na cidade pós-moderna. Finisterra Revista Portuguesa de Geografia, XLI(81): 33-56.

Camus J-Y (2004) Le cirque, la quadrature du cercle. Mémoire de DESS Développement culturel et direction de projet, Université Lyon 2, Lyon.

Comeau Y (2004) Les contributions des sociologies de l'innovation à l'étude du changement social. Innovations Sociales et Transformations des Conditions de Vie. Actes du Colloque - 16 Avril 2004, Cahiers du CRISES, Collection Études théoriques, ET0418: 29-44. 
En Piste - Regroupement National des Arts du Cirque (2005) Le fabuleux destin des arts du cirque à Montréal. Projet de Politique de Développement Culturel de la Ville de Montréal, Mémoire présenté à L'Office de consultation publique de Montréal le 14 février, Montreal.

Florida R (2008) Who's your city?: How the creative economy is making where to live the most important decision of your life. Basic Books, New York.

Florida R (2002) The rise of the creative class: And how it's transforming work, leisure, and everyday life. Basic Books, New York.

Gertler M (2004) Creative cities: what are they for, how do they work, and how do we build them? Canadian Policy Research Networks, Ottawa.

Hall P (2000) Creative cities and economic development. Urban Studies, 37(4): 639-649.

Jacob P (2002) Le cirque, du theatre équestre aux arts de la piste. Larousse, Paris.

Klein J-L, Harrison D (eds.) (2007) L'innovation sociale - emergence et effets sur la transformation des sociétés. Presses de l'Université du Québec, Montreal.

Landry C (2000) The creative City: a toolkit for urban innovators. Earthscan, London.

Ley D (2003) Artists, aestheticisation and the field of gentrification. Urban Studies, 40(12): 2527-2544.

Martinelli F, Moulaert F, Swyngedouw E, Ailenei O (2003) Social innovation, governance and community building - Singocom - Scientific Periodic Progress Report Month 18, edição electrónica http://users.skynet.be/bk368453/singocom/index2.html [Acedido em 10 de Setembro de 2006]

Moulaert F, Demuynck H, Nussbaumer J (2004) Urban renaissance: from physical beautification to social empowerment. Lessons from Bruges - Cultural Capital of Europe 2002. City, 8(2): 229-235.

Ruby C (2003) Quels lieux de rencontre démocratiques? Des lieux de rencontre au lieu de la rencontre. EspacesTemps.net, Textuel, 05.06.2003, edição electrónica. http://espacestemps.net/ document433.htm [Acedido em 9 de Junho de 2007]

Ruby C (2002) L'art public dans la ville. EspacesTemps.net, Actuel, 01.05.2002, edição electrónica http://espacestemps.net/document282.html [Acedido em 9 de Junho de 2007]

Santos J (1981) O circo e o pensar, ensaios sobre a educação II, Livros Horizonte, Lisboa.

Scott A (2006) Creative cities: conceptual issues and policy questions. Journal of Urban Affairs, 28(1): 1-17.

Smiers J (2005) Arts under pressure: promoting cultural diversity in the age of globalization. Zed Books, London.

TOHU (2008) Circus * Earth * People - A sustainable development initiative in the heart of the Saint-Michel Neighbourhood. TOHU, La Cité des Arts du Cirque, Montreal. 